\title{
Creative Marketing as a Strategic Introduction to Enhance the Competitive Advantages in Jordanian Service Organizations: A Case Study
}

\author{
Ali Falah Al-zoubi ${ }^{1}$ \\ ${ }^{1}$ Faculty of Business, Arab Amman University, Jordan \\ Correspondance: Ali Falah Al-zoubi, Marketing Department, Faculty of Business, Arab Amman University, \\ Amman, Jordan. E-mail: alzoubifali@yahoo.com
}

Received: February 1, $2017 \quad$ Accepted: February 21, $2017 \quad$ Online Published: March 2, 2017

doi:10.5539/ijms.v9n2p78

URL: http://doi.org/10.5539/ijms.v9n2p78

\begin{abstract}
The study aims at identifying the concept as well as the factors of creative marketing in service organizations and recognizing the development in the service sector at a global level. The sample of the study was comprised of (16) Jordanian service organizations that were intentionally chosen. The sampled organizations represent $16 \%$ of the population. The study is an attempt to find out the role of creative marketing in reaching the competitive advantage in Jordanian service organizations while depending upon the basic factors of creativity in the marketing mix (7Ps). The significance of the study lies in the examination of the efficiency of creative marketing at the organizational level. Creativity refers to the trends adopted by the entrepreneurial organizations, which seeks to provide creative products and services while positively making a change in the competitive base. The creative process in organizations is shaped through researching and developing creative ideas in order to increase profits and investment revenues of successful products and services as well as improving the strategic status. The study has come out with several findings and recommendations that include: the necessity of establishing a department for marketing in the organization, defining whose responsibility it is to develop and to create new products by building a creative personnel that is highly educated in marketing, creating a balance in terms of creativity among various marketing areas and not only focusing on the product in spite of its significance, and structuring an administrative branch that is specialized in creativity particularly in marketing creativity in each of the sampled organizations. It was discovered that these organizations administrative branches sought to find out effective marketing ideas, filter them, evaluate them, and turned the useful ideas into innovative products and developed tangible products mainly to serve the customers of the organization.
\end{abstract}

Keywords: creativity, creative administration, creative marketing, marketing mix, strategy, competitive advantages, service organization, Jordan

\section{Introduction}

The development and prosperity of the developed countries occurred due to their interest in creativity, innovative marketing, and their support as well as the encouragement of new ideas by facilitating the appropriate conditions for them. Scholars believe that the world is currently experiencing a vast economy, which is dependent on intangible output represented in computer codes, media content, design, and information services. The majority of organizations operate in an environment characterized by fierce competition, constant change in the needs and desires of customers, and enormous developments in technology. Accordingly, they need to rely on innovation in order to strengthen their development and research and to know how to take advantage of the individual and collective capacity to gain access to innovation and excellence in their activities.

Services have several characteristics that add to the creative process in this sector. Creative marketing in the field of services can be in the form of proposing a new service or a new technique in production and service delivery. The creativity of the service organization is mostly based on the customers' point of view or the interactions among the employees and the customers. Creativity in the service sector is directed by the customers, which is termed as "customer-driven approach" that can be developed by organized thinking. The need of an organization for creative marketing is represented by its capability to communicate with its customers and to fulfill their needs through its current products or the development of new products that constantly meet the customers' changing 
tastes. Unlike other organizations operating in other fields, creative marketing in service organizations has special characteristics due to the nature of their service and activities. Several studies indicate that creative marketing in the service sector is low though creative marketing is the most prominent tool used to gain success in producing and marketing high quality commodities and contributing to create new opportunities and markets (Allen, 2013).

\subsection{The Problem of the Study}

The absence of creative marketing in the elements of marketing mix in service sector (7Ps) or the focus on one of these elements such as the service ignoring the other elements, which has a negative effect on the competitive advantages, and capabilities of an organization. Creative marketing is a constant competitive advantage for any organization that has strategic value and is a flexible source. Creative marketing is considered a unique, valuable resource for any organization. The study attempts to examine the role of creative marketing in achieving a competitive advantage in Jordanian service organizations since constant creations protect the organization from being exposed to risky competition. To do so, Jordanian service organizations need to adopt the basic factors of creativity represented by elements of the marketing mix (7Ps).

\subsection{Questions of the Study}

Based on the problem of the study, the following questions have been developed:

- Are the sampled organizations aware of creative marketing and creation in the elements of the marketing $\operatorname{mix}$ ?

- Is the market share of the organization a result of creativity in the elements of the marketing mix?

- Do the sampled organizations implement the principle of creative marketing holistically in the marketing mix as well as in the process of enhancing competitive advantages?

\subsection{The Importance of the Study}

- Creative marketing is one of the variables that has influence on the capability of service organizations to grow, prosper, and continue. The significance of creative marketing increases especially in world of globalization and competition.

- To examine the role of creativity in the elements of marketing mix to create an environment that is appropriate for marketing entrepreneurship in service organizations.

- This study pays attention to creative marketing as being one of the elements that contributes to achieving long-term entrepreneurship in a dynamic environment that is full of competition.

- This study investigates the role of administrated creative marketing in adding the competitive advantage to the organization and demonstrates the factors influencing the administration of the creation process as a culture in the organization.

- The study focuses on effective marketing performance within the organization.

- The creative process in an organization is shaped by digging for ideas and developing them in order to increase revenues and profits of investments.

- The significance of creativity has surfaced in light of fierce global competition and the growth of customers' needs.

\subsection{The Objectives of the Study}

- Identifying the concept of creative marketing and its fundamentals in service organizations.

- Identifying the current developments in the service sector at a global level.

- Presenting an academic theoretical framework for creative marketing and its elements in the service market mix.

- $\quad$ Presenting a theoretical framework for the process of enhancing competitive advantages.

- This study introduces some recommendations for service organizations in light of the results of the study.

\subsection{The Model and the Variables of the Study}

To explain the problem of the study and achieve its objectives, a default model should be built in order to specify the independent variable (creative marketing) and the dependent variables (the processes of competitive advantages) as illustrated in the Figure 1 below: 


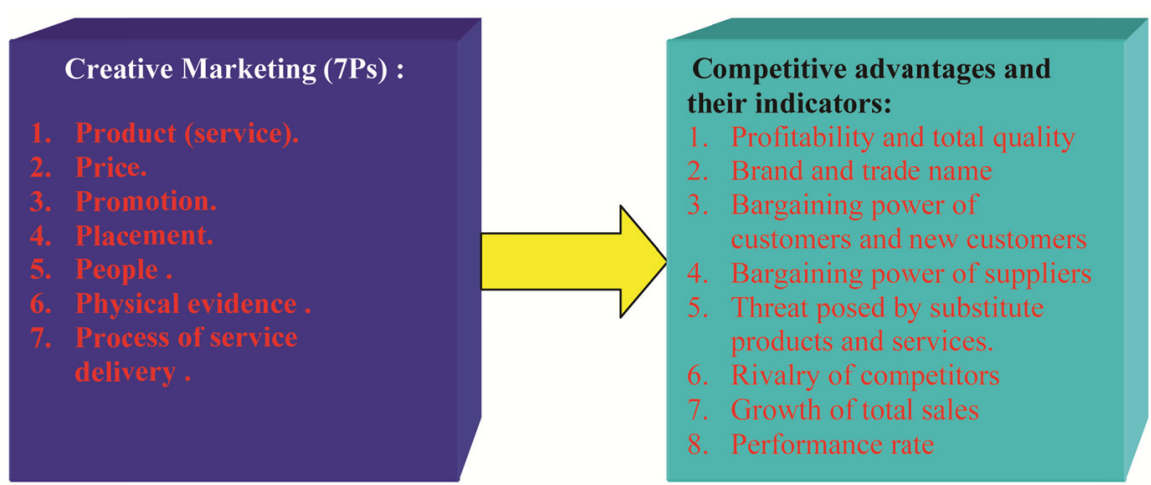

Figure 1. The model of the study

Source: Prepared by the researcher, 2016.

\subsection{Hypothesis of the Study}

To achieve the objectives of the study, the researcher applies a set of hypotheses:

- The first hypothesis: There are no significant differences when the level of significance $(\alpha \leq .05)$ between the averages answers respondents to the dimensions and variables study differences.

- The second hypothesis: There is a significant correlation When the level of significance $(\alpha \leq .05)$ between the creative marketing and enhancing the competitive advantages in the sampled organizations.

The third hypothesis: There is a significant positive when the level of significance $(\alpha \leq .05)$ effect of creative marketing on enhancing the competitive advantages in the sampled organizations.

\subsection{The Limitations of the Study}

The limitations of the study can be classified into the following in terms of time, place, and subject:

- Time Limitations: the field study has been conducted from (1/5/2016) up to (1/11/2016).

- Place Limitations: the study has been conducted on 16 service organizations in Amman

- Subject limitations: the study is restricted to creative marketing and competitive advantages.

\section{Method}

\subsection{Methodology}

The analytical descriptive approach was adopted in the study.

\subsection{The Tool of the Study}

The questionnaire is comprised of three parts: the first part consists of a group of questions/statement related to personal information about the members of the sample. The second part includes (8) questions/statements related to creative marketing. As for the third part, it includes (12) questions about the competitive advantage. The answers of the questionnaire were based on Likert Scale. The questionnaire and the personal interview were mainly used to collect data.

\subsection{Statistical Methods Used}

I have used researcher in the study Frequency distribution, mean, and standard deviation were used to analyze the data and the variables of the study. T-test and ANOVA were used to test the hypotheses of the study. The reliability of the questionnaire was proven using Chronbach Alpha test, in which reliability coefficient of the statements related to creative marketing was $(\mathrm{Alpha}=0.92)$ while the reliability coefficient of the statements related to competitive advantage was (Alpha $=0.92$ ). Kolmogrov-Smirov test was used to prove the normal distribution of the data. P- Value was (null) - that is above (0.05) for each statement in the questionnaire, proving that the data follow the normal distribution.

\subsection{The Population of the Study}

The population of the study represents the Jordanian service organizations specialized in tourism, travelling, telecommunication, hospitals, and banks, of which 16 ones (16\% of the population) have intentionally been chosen as the sample of the study. 


\subsection{The Sample of the Study}

The study includes general managers, their assistants, IT heads, marketing and sales heads, research and development heads, and HR heads. (80) questionnaires have been distributed, (5) questionnaires for each company. (70) questionnaires have been returned, and (6) questionnaires have been excluded due to their invalidity. Accordingly, (64) questionnaires ( $88 \%$ of the total distributed questionnaires) have been valid to analyze.

\section{Theoretical Framework of the Study}

\subsection{The Concept of Creativity}

Creativity is defined as "doing what has never been done before and that includes understanding, invention, and investing". Kok (2007, pp. 16-17) defines it "seeing what other see but thinking differently about it". Creativity also includes "producing particular commodities and services or following new inputs which have never been used- which means adapting to new technological changes" (Khudair, 2010, p. 288). New British Encyclopedia defines creativity as "the ability to find out a new solution for a problem, a new tool, artistic impact, or a new style" (Fathi, 2002, p. 20).

\subsection{Areas of Creativity}

- Creating a new opportunity to develop a new idea.

- Developing a new policy to cause the right change to find out an idea for a new competitive advantage for the administration

- using a new way to build a new operating process or a new technology

- introducing new links between working units (Sami Hareez, 2008, p. 199)

\subsection{Conditions of Creativity}

The conditions of creativity are consistent with a number of factors appropriate for the organization. They are analyzed into three levels: (Soparnot \& Steven, 2007, p. 96)

- The organization needs to create an internal network of relationships among individuals. This is termed as the internal level.

- The organization then needs to create a special framework related to the factors, and it is called as the organizational level.

- Finally, the organization needs to mainly focus on the individuals who have the potentials to create. Creativity has a social dimension, so there is what is called "social creativity", which allows improving life circumstances of family, market, salaries, and security, all connected to general and social policies of a particular society.

\subsection{Requirements of Creativity}

Since there are no general strategies for creating creative organizations, a number of requirements for creativity can be suggested to make it more achievable. Scholars have summed up the requirements as follows:

\subsubsection{Handy's Model}

Handy is considered to be one of the pioneers who called for replacing the conventional skills with a new easily applicable skill such as creativity appearing through generating ideas. The following formula includes the basic factors constituting an ideal model for the organization of the future:

Intelligence + information + ideas $=$ an added value (Braffin, 2008, p. 88)

\subsubsection{Jouis Model}

20/80 Rule: It is based on the following formula:

$80 \%$ of an encouraging environment for creativity $+20 \%$ of helping tools $=$ high capability for creativity

At least, both factors should be included in any organization to be creative. (Braffin, 2008, p. 89)

\subsection{Creative Marketing}

Creative Marketing is defined as any distinguished marketing action which makes the organization different from the others in the market (Lammer, \& others, 2009, p. 11). It is also defined as the "successful use of the new ideas in the field of marketing" (Abu, 2003, p. 11).

Moore's definition of creative marketing is customer-oriented. To him, creative marketing improves the operations which have influence on customers through marketing means of communication such as websites, 
viral marketing, deals done immediately with the customers (e-commerce) (Moore, 2004, p. 86).

Creative marketing is also defined as "launching new unconventional ideas in marketing practices" (Lammer, \& others, 2009, p. 52). The British institute define it as "the creative administrative position motivating trading and hiring based on the needs of the clients and conducting researches to satisfy those needs" (Lammer, \& others, 2009, p. 47). Organization for Economics for Co-operation and Development (OECD) has come up with the most comprehensive definition for creative marketing as "the implementation of new marketing ways making significant changes in the design of products, whether in manufacturing, pricing, promoting, or distributing" (www.stats.oecd.org). Further, creative marketing refers to the adoption of new innovative ideas in the field of marketing in order to develop the current products or new products by being oriented with recent ideas and trends (Singh \& Waddell, 2014, p. 87).

\subsection{Areas of Creativity in the Elements of Marketing Mix}

Creativity in the marketing mix refers to introducing new unfamiliar ways and ideas to the elements of the marketing mix (product, price, promotion, and placement). Creativity in the elements of marketing mix is dealt with in this research as being implemented in small non-service businesses:

\subsubsection{Creative Products (Services)}

It means generating new ideas based on the inspiration of the creator himself in order to introduce a new product or constantly improve the features of the current product in a way that satisfies the needs, desires and expectations of the customers and putting them into action. Creative products refer to introducing new products that have distinguished functional features (http//:www.Science.doe.gov). Creativity in products includes causing significant changes in the design of the product adding a new value that attracts more customers (Bonnal, 2009, p. 46). It also includes making a basic change in the features of the products making it more special and unique. Creativity in product can be shown through the following matrix illustrated in the Figure 2 below:

\begin{tabular}{|c|c|}
\hline \multicolumn{2}{|c|}{ Creativity } \\
\hline old & new \\
\hline CREATIVE PRODUCTS & PURE CREATIVE PRODUCTS \\
AND MERGE THEM INTO THE MARKET & NO CREATIVITY \\
\hline ACREATIVE MARKET MIX & \\
\hline
\end{tabular}

Figure 2. The matrix of creative products

Source: Bonnal, 2009, p. 48.

The matrix is explained in the following:

1). Pure creative products (Bonnal, 2009, p. 57).

2). Creative products and its mixing with marketing.

3). Pure creative marketing.

4). No creativity: introducing the current product without being changed using the conventional marketing mix which doesn't appeal to the current changes in the market.

\subsubsection{Creative Pricing}

Pricing is considered to be the most difficult task for the managers in any organization since it is subject to a number of constantly changing factors which go beyond the control of the organization. A number of pricing methods based on demand, cost, competition, and product shaping (Bonnal, 2009, p. 48) can do creative pricing

\subsubsection{Creative Promotion}

It means, "introducing new ideas and ways as well as introducing new ways to raise the customers' understanding and awareness of the products and encourage them to buy". Holding special events to promote for the products is an example of creative promotion. Creativity in the field of promotion can be studied as follows: creative marketing by personal sales, creative marketing in the field of commercials and increasing sales, creative marketing in the field of public relations, creative marketing in the field of direct marketing, and creative marketing in the field of publishing about products (Ali, 2016a).

\subsubsection{Creativity in Placement (Distribution)}

It means introducing new ways and methods in distributing products. The process of introducing a product into 
the market passes a series of distribution channels before being delivered to the customers. The role of the organization is to create new distributing channels instead of the conventional ones. The strategies of creative distributing can be classified as follows: (Sanjeef \& Rajesh, 2005, p. 254)

\subsubsection{Distribution According Methods}

It is divided into two strategies: Push strategy and Pull Strategy. (Sanjeef \& Rajesh, 2005, p. 249)

3.6.4.2 Distribution according to Intensity.

Creative can undergo simple modifications in the area of services including the following levels:

\subsubsection{Creative Service}

It may include introducing new services to the current markets such as the insurance service added by many banks and extending the hours of service in some organizations.

\subsubsection{Creative Processes and Operations}

It includes renewing the conventional procedures of production and delivery.

Creative Market: it includes finding new spaces in the market or introducing a new industry such as adding new dishes to the menu, finding new aviation routes, meeting the needs of various sectors in the market.

\subsubsection{Creative Working Model}

It includes creating a new meaning for work including the previous three types.

What distinguishes the service sector from others is the difficulty to separate the service and the production system. In order to simplify that the following levels are dealt with here:

a. Creativity in developing a new service. (Na'eem, 2003, p. 132)

b. Creativity in process designing (Cook, 2007, pp. 41-42)

c. Creating a strategy to develop a new service.

\subsection{Managing Creative Marketing}

Creative marketing is one of the modern arts in the field of management. It is similar to the other departments in all dimensions, whether in tasks (planning, organizing, coordinating, leading, monitoring) or in strategic goals. However, there is one difference related to the nature of creative management, which requires special material to keep going efficiently.

Creative management is one of the secrets of success in an environment characterized by fierce competition, and it is the most important source to get creative projects successfully done. Creative projects are characterized by ambiguity. The figure below illustrates the relevant powers related creative management (Ali, 2016a).

Creative Management is defined as a group procedures and choices taken and implemented by the organization focusing on the creative process; then the decision is made to launch the creative project in the light of good leadership in the organization (Bonnal, 2009, p. 232). In the long term, creativity is one of the strategic factors needed to be considered in creative management. Gary Hamel defines creative marketing management as "the transition away from the conventional managerial and organizational processes and practices adapting them in a way that serves the management and the work effectively and efficiently.

\subsection{Factors of Creativity in Service Organizations}

There are a number of factors related to electronic paying ways in banking organizations:

\subsubsection{The Sector}

There are a number of factors influencing the level of creativity in service organization including:

- The Structure of the Market: it is influenced by a number of factors including:

- Service Network.

- Market Size.

- Government Structure. (Benfratello et al., 2008, p. 199)

- The Infrastructure. (Benfratello et al., Ibid, p. 199)

- Adaptability.

- Cooperation. 
- The Level of Creativity. (Ali, 2016b)

\subsubsection{Economy}

The economy of a country is classified based on the global competitiveness index in three stages which are:

- Worker-driven Economy

- Qualification-driven Economy

- Creativity-driven Economy. Creativity is one of the main powers directed to develop the Economy. Many scholars agreed on that fact that the growth in production, which can be greatly directed by creativity, inevitably leads to a growth in economical welfare (Sanjeef \& Rajesh, 2005, p. 17).

\subsubsection{Law and Legislation}

When law and legislation is innovation-friendly, creativity in service organizations will be successfully launched. Legislations and industrial sectors can complement each other leading to an integrated series of successful services.

\subsubsection{Politics}

The political support for creative marketing and technology includes:

- Establishing organizations and research programs

- Offering material as well as immaterial incentives.

- Launching national programs for creative marketing and technology.

\subsubsection{Technology}

Infrastructure cannot be isolated from telecommunication structures, ICT Infrastructure, various sectors, and information technology in terms of devices, solutions, programs, applications, trained human resources, and professional occupations.

3.8.6 Organization (Chen, 2006, p. 132)

\subsubsection{Society}

Creative services provides individuals with benefits making their lives easier and safer, whether customers or retailers, cuts costs, and supports the economical welfare by activating trade (Chen, 2006, p. 17)

\subsection{The Relationship between Creative Marketing and Competitive Advantage}

\subsubsection{The Strategic Analysis for the Organization}

The strategy of any organization needs time to be implemented in the long term. Accordingly, the organization needs to predict the strategic actions for the next five years. To make the best decision, the organization needs to follow a number of procedures, the classical strategic analysis, the competitive analysis, and the model for competitive strategies (Ali, 2016a).

The Classical Strategic Analysis: it includes two sub-analyses: an internal analysis for the organization environment and an external analysis for the organization. The figure below illustrates the analyzing process:

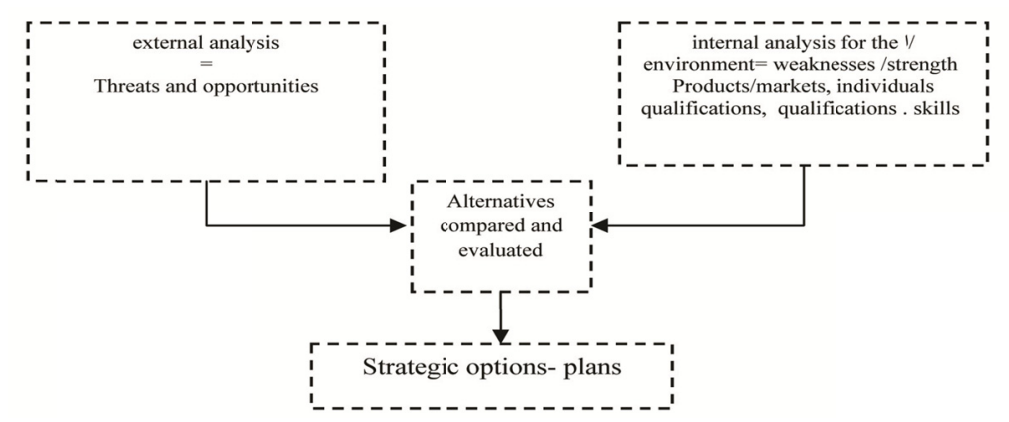

Figure 3. The classical strategic analysis 


\subsubsection{Competitive Analysis}

It aims at analyzing the role of competitiveness in enabling the organization to take a position among its rivals in the market (Garibaldi, 2006, p. 93). It is based on knowing the competition obstacles that come in the way of the organization and how to face these obstacles and turn them into opportunities. It also includes specifying the right strategies and cut the way from being competed by other rivals in a particular sector. If does so, the organization knows the right track toward competitiveness or draws what is termed as the map of competition.

\subsubsection{The Competitive Strategy as the Basis of Competitive Advantage}

The competitive strategy can be identified as: "an integrated set of actions that lead to a continuous and sustained advantage over competitors", and consists of three main components: a way to compete (Nabil, 2008, pp. 19-21). Porter has suggested three strategies to compete in order to achieve the best performance (Nabil, 2008, pp. 118-124).

A. Strategy of entrepreneurship in costing: This strategy aims at achieving lower costs compared to the competitors (Porter, 2009, p. 2).

B. Strategy of Discrimination: there are many entrances to differentiate the product of an organization from others' such as different shapes of a product, excellent service, spare parts, engineering design and performance, unusual specialized quality, the creditability of a product, technological entrepreneurship, a wide range of provided services, a holistic error in the products, and good reputation.

C. Strategy of Concentration: it aims at structuring a competitive advantage to have a better status in the market through meeting the needs of a group of customers, focusing on a specific geographic market, or emphasizing the particular uses of a product.

According to Porter, a strategy aspires to have a constant and relevant status of specific powers including the framework of the competitive sector (Porter, 2009, p. 11). These forces are called the forces of competition, which can be represented by the following Figure 4:

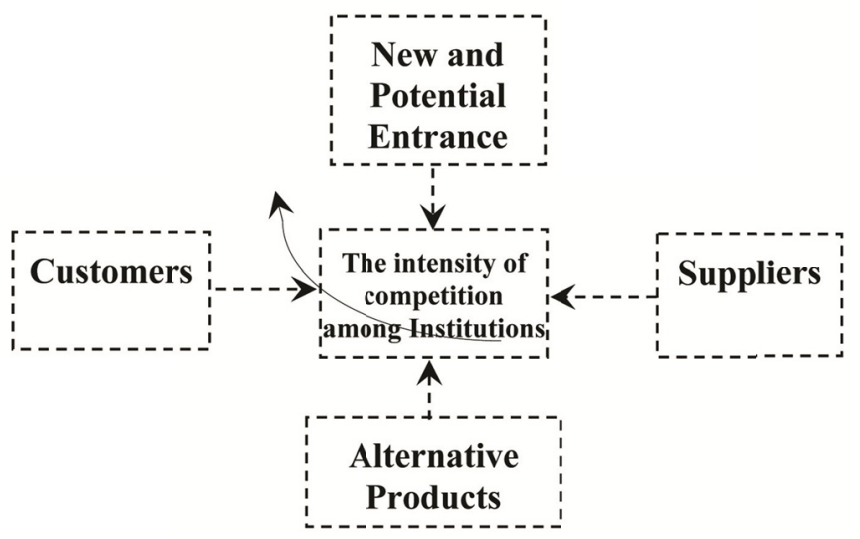

Figure 4. The five competitive powers

Source: Porter, 2002, p. 4.

\subsubsection{The Relation between Creative Administration and Competitive Advantage}

The prominent success, just by itself, resulted from the application of creativity can accomplish the competitive advantage leading to consolidate the organization and its characteristics. This encourages the organization to use the sources of knowledge and technological potentials more and more, and this applies to experience in order to implement new techniques related to the ways of selling products/services. This trend can be considered at the level of private organizations and as a source of national economic growth. For instance, the Administration of Technology and Sciences in the United Kingdom considers those processes to be the engine of new economy since it turns the ideas and knowledge into products and services. Through different functions, creativity contributes to the field (Ali, 2016b). The relation between the marketing creativity and the competitive advantages in the organization is illustrated in the figure below (Ying, 2005, p. 23): 


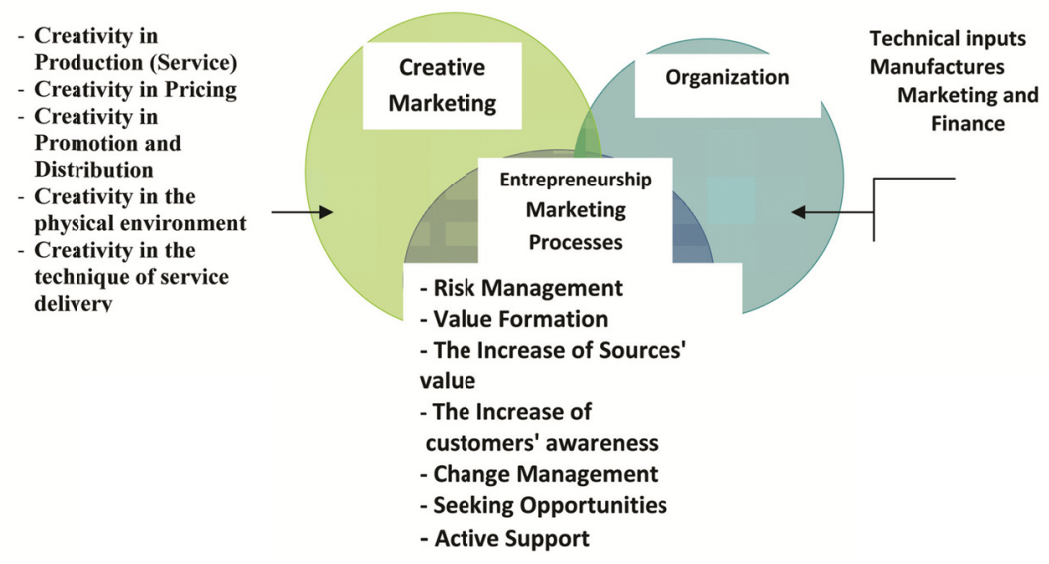

Figure 5. The relation between creative marketing and the competitive advantages

Source: Freely adopted by the researcher based on (Anisa, 2006, p. 23).

\section{Practical Framework of the Study}

\subsection{Data Analysis}

The researcher attempts to analyze the data and discuss the results in order to show the levels of the sampled responses, which are comprised of 64 executive personnel in 16 specialized company. To evaluate their awareness and familiarity with the main standards of marketing creativity and competitive adjectives, statistical tools were used such as the means, standard deviation, frequencies, and percentages.

Analyzing the responses related to the demographic factors of the members of the sample-Part one:

- Table 1 proves that $31 \%$ of the sample represents post graduates, whereas, $60 \%$ of the sample represents graduates as well as $9 \%$ of the sample represents high secondary holders.

- Table 2 illustrates that $5 \%$ of the sample represents personnel with experience of less than 5 years, $1 \%$ represents personnel with experience of 5 to 10 years, $36 \%$ represents personnel with experience of 11 to 20 years, $29 \%$ represents personnel with experience of 21 to 30 years, and $8 \%$ represents personnel with experience of more than 30 years. Accordingly, the majority of the members of the sample have long-term experience.

Table 3 clarifies that the age of $5 \%$ of the sample is less than 25 years, $33 \%$ of the sample ranges between 25 and 34 years, $20 \%$ of the sample ranges between 35 and $44,26 \%$ of the sample ranges between 45 and 54 , and $12 \%$ of the sample is 55 years and more.

Table 1. The classification of the members of the sample according the academic qualification

\begin{tabular}{lll}
\hline Qualification & Frequency & Percentage \\
\hline Post Graduates & 19 & $30 \%$ \\
Graduates & 37 & $57 \%$ \\
High School holders & 8 & $13 \%$ \\
\hline Total & 64 & $100 \%$ \\
\hline
\end{tabular}

Table 2. Classification of the members of the sample according to the experience years

\begin{tabular}{lll}
\hline Experience Years & Frequency & Percentage \\
\hline Less than 5 years & 4 & $6 \%$ \\
5-10 years & 13 & $23 \%$ \\
11-20 years & 24 & $36 \%$ \\
21-30 years & 18 & $28 \%$ \\
More than 30 years & 5 & $7 \%$ \\
\hline Total & 64 & $100 \%$ \\
\hline
\end{tabular}


Table 3. Classification of the members of the study according to the age

\begin{tabular}{lll}
\hline Age & Frequency & Percentage \\
\hline Less than 25 years & 6 & $10 \%$ \\
$25-34$ & 23 & $35 \%$ \\
$35-44$ & 12 & $19 \%$ \\
$45-54$ & 15 & $23 \%$ \\
55 and more & 8 & $13 \%$ \\
\hline Total & 64 & $100 \%$ \\
\hline
\end{tabular}

\subsection{The Analysis of Responses: The Variable of the Competitive Advantages}

The numbers in table 4 indicate that the trends (responses) of the sample are negative towards the 17 and 19 sections since their means are less than the mean of the measurement tool (3). Accordingly, it is clear that there is a lack of information and knowledge related to the quality and development of the technology used by the competitors as well as a lack of the awareness of the competitors' future aspirations, which gives the competitors a competitive advantage. On the other hand, the trends (responses) of sample are positive towards the sections left since their means are more than the mean of the measurement tool. The concluded mean and the standard deviation of the study questions are summarized in the table below:

Table 4. The classification of frequency, mean, and standard deviation of the sample's responses for the competitive advantages $(\mathrm{N}=64)$

\begin{tabular}{|c|c|c|c|c|c|c|c|c|c|c|c|c|}
\hline \multirow{3}{*}{$\begin{array}{l}\text { The Number of } \\
\text { the Indicator in } \\
\text { the Questionnaire }\end{array}$} & \multicolumn{10}{|c|}{ Response Measurement } & \multirow{3}{*}{ Mean } & \multirow{3}{*}{$\begin{array}{l}\text { Standard } \\
\text { Deviation }\end{array}$} \\
\hline & \multicolumn{2}{|c|}{ Absolutely agree } & \multicolumn{2}{|c|}{ Agree } & \multicolumn{2}{|c|}{ Neutral } & \multicolumn{2}{|c|}{ Don't agree } & \multicolumn{2}{|c|}{ Never agree } & & \\
\hline & $ت$ & $\%$ & $ت$ & $\%$ & $ت$ & $\%$ & $ت$ & $\%$ & $ت$ & $\%$ & & \\
\hline 1 & 38 & $60 \%$ & 17 & $30 \%$ & 2 & $3 \%$ & 7 & $7 \%$ & - & - & 2.620 & 0.801 \\
\hline 2 & 37 & $63 \%$ & 20 & $32 \%$ & 2 & $3 \%$ & 5 & $2 \%$ & - & - & 3.500 & 0.810 \\
\hline 3 & 50 & $76 \%$ & 10 & $18 \%$ & 2 & $3 \%$ & 2 & $3 \%$ & - & - & 2.260 & 0.980 \\
\hline 4 & 49 & $73 \%$ & 12 & $22 \%$ & 2 & $3 \%$ & 1 & $2 \%$ & - & - & 4.080 & 0.850 \\
\hline 5 & 40 & $60 \%$ & 20 & $36 \%$ & - & - & 4 & $6 \%$ & - & - & 3.480 & 1.123 \\
\hline 6 & 47 & $70 \%$ & 12 & $22 \%$ & - & - & 5 & $7 \%$ & - & - & 3.900 & 0.810 \\
\hline 7 & 15 & $30 \%$ & 42 & $60 \%$ & 2 & $3 \%$ & 5 & $7 \%$ & - & - & 3.760 & 0.933 \\
\hline 8 & 18 & $32 \%$ & 41 & $61 \%$ & - & - & 3 & $4 \%$ & - & - & 3.860 & 0.804 \\
\hline 9 & 10 & $18 \%$ & 50 & $76 \%$ & - & - & 4 & $6 \%$ & - & - & 4.100 & 0.926 \\
\hline 10 & 12 & $22 \%$ & 51 & $76 \%$ & - & - & 1 & $2 \%$ & - & - & 3.820 & 0.914 \\
\hline 11 & 20 & $36 \%$ & 42 & $60 \%$ & - & - & 2 & $3 \%$ & - & - & 3.640 & 1.067 \\
\hline 12 & 12 & $22 \%$ & 49 & $74 \%$ & - & - & 3 & $4 \%$ & - & - & 3.760 & 0.842 \\
\hline $\begin{array}{l}\text { The Average of } \\
\text { the Percentage }\end{array}$ & 38 & $48.16 \%$ & & $48.16 \%$ & & & & $3.68 \%$ & & & 42.780 & 0.8859 \\
\hline The General Mean & nd $\mathrm{St}$ & Ird Devia & & & & & & & & & 3.565 & 0.738 \\
\hline
\end{tabular}

\subsection{The Analysais of Responses: The Variable of Marketing Creativity}

Table 5. Frequency distribution, mean, and standard deviation of the sampled responses for marketing creativity $(\mathrm{N}=64)$

\begin{tabular}{|c|c|c|c|c|c|c|c|c|c|c|c|c|}
\hline \multirow{3}{*}{$\begin{array}{l}\text { The Number of } \\
\text { the Indicator in } \\
\text { the Questionnaire }\end{array}$} & \multicolumn{11}{|c|}{ Response Measurement } & \multirow{3}{*}{$\begin{array}{l}\text { Standard } \\
\text { Deviation }\end{array}$} \\
\hline & \multicolumn{2}{|c|}{ Absolutely agree } & \multicolumn{2}{|c|}{ Agree } & \multicolumn{2}{|c|}{ Neutral } & \multicolumn{2}{|c|}{ Don't agree } & \multicolumn{2}{|c|}{ Never agree } & \multirow[t]{2}{*}{ Mean } & \\
\hline & $ت$ & $\%$ & $ت$ & $\%$ & $ت$ & $\%$ & $ت$ & $\%$ & $ت$ & $\%$ & & \\
\hline 1 & 40 & $60 \%$ & 17 & $31 \%$ & 3 & $5 \%$ & 2 & $4 \%$ & 2 & $4 \%$ & 4.640 & 0.067 \\
\hline 2 & 38 & $56 \%$ & 19 & $35 \%$ & 2 & $4 \%$ & 3 & $5 \%$ & - & & 4.760 & 0.842 \\
\hline 3 & 17 & $31 \%$ & 40 & $55 \%$ & 7 & $14 \%$ & - & - & - & & 4.140 & 0.876 \\
\hline 4 & 19 & $35 \%$ & 38 & $56 \%$ & 2 & $4 \%$ & 5 & $9 \%$ & - & & 3.820 & 0.998 \\
\hline 5 & 50 & $73 \%$ & 10 & $18 \%$ & - & - & - & - & 4 & $9 \%$ & 3.900 & 0.948 \\
\hline 6 & 10 & $18 \%$ & 50 & $73 \%$ & - & - & 2 & $5 \%$ & 2 & $4 \%$ & 3.075 & 0.971 \\
\hline 7 & 18 & $32 \%$ & 41 & $66 \%$ & 4 & $9 \%$ & 1 & $2 \%$ & - & - & 3.860 & 0.804 \\
\hline 8 & 19 & $35 \%$ & 38 & $56 \%$ & 2 & $4 \%$ & 5 & $9 \%$ & - & & 3.000 & 0.998 \\
\hline $\begin{array}{l}\text { The Average of } \\
\text { the Percentage }\end{array}$ & - & $44.58 \%$ & - & $4.615 \%$ & - & $3 \%$ & - & $3.85 \%$ & - & $2.17 \%$ & 24.335 & 0.471 \\
\hline \multicolumn{5}{|c|}{ The General Mean and Standard Deviation } & & & & & & & 4.55 & 0.78 \\
\hline
\end{tabular}




\subsection{Testing the Hypotheses}

The First Hypothesis: There is a significant relation between marketing creativity and the competitive advantages of the organization from the members of the sample's points of views.

Table 6. Multiple deviation between marketing creativity and competitive advantages of the organization

\begin{tabular}{lllll}
\hline Relation & The Result of Null Hypothesis & SIG F & F Tabulated & F calculated \\
\hline 0.889 & Reject & 0.000 & 3.14 & 66.076 \\
\hline
\end{tabular}

Since the Multiple Deviation Testing has been used, the results on the computer in table 6 indicate that the value of the calculated F equals 66,076, which is more than its tabulated value. Since the basis of the relation (decision) accepts the null hypothesis (H0) if the calculated value is less than the tabulated value. Otherwise, it rejects the null hypothesis (H0) and accepts the alternative hypothesis (Ha) if the calculated value of is more than the tabulated value. If so, there is a strong / significant relationship between marketing creativity and competitive advantages of the organization due to the high value of $\mathrm{R}=0.889$.

Table 7. Simple derivation between marketing creativity and competitive advantages of the organization

\begin{tabular}{lllll}
\hline Relation & The Result of Null Hypothesis & SIG T & T Tabulated & Calculated T \\
\hline 0.622 & Reject & 0.000 & 2.34 & 5.344 \\
\hline
\end{tabular}

Since the simple deviation has been used, the results on the computer in the previous table indicate that the value of the calculated T equals 5,344, which is more than its tabulated value. Since the basis of relation (decision) accepts the null hypothesis (H0) if the calculated value is less than the tabulated value, and it rejects the null hypothesis ( $\mathrm{H} 0)$ and accepts the alternative hypothesis (Ha) if the calculated value is more than the tabulated value. If so, there is a significant (strong) relationship between marketing creativity and competitive advantages of the organization due to the high value of $\mathrm{R}=0.622$.

The Second Hypothesis: There is a significant relation between marketing creativity and the competitive advantages of the organization from the members of the sample's points of views.

Table 8. Simple deviation between marketing creativity and competitive advantages

\begin{tabular}{lllll}
\hline Relation & The Result of Hypothesis & SIG T & T Tabulated & Calculated T \\
\hline 0.832 & Reject & 0.000 & 2.08 & 4.997 \\
\hline
\end{tabular}

Since the simple deviation has been used, the results on the computer in the previous table indicate that the value of the calculated T equals 4,997, which is more than its tabulated value. Since the basis of relation (decision) accepts the null hypothesis (H0) if the calculated value is more than the tabulated value, and it rejects the null hypothesis ( $\mathrm{H} 0)$ and accepts the alternative hypothesis $(\mathrm{Ha})$ if the calculated value is more than the tabulated value. If so, there is a significant (strong) relationship between marketing creativity and competitive advantages of the organization due to the high value of $\mathrm{R}=0.832$. Accordingly, marketing creativity has an impact on the competitive advantage.

The Third Hypothesis: the statistical analysis reveals that there are significant differences between marketing creativity and competitive advantages from the members of the sample's points of views due to the personal factors.

Table 9. ANOVA to test the characteristics of the sample

\begin{tabular}{llll}
\hline Variable & F Calculated & F Significant & Result \\
\hline Academic Qualification & 9.822 & 0.003 & There are differences \\
Experience & 22.77 & 0.001 & There are differences \\
Age & 7.258 & 0.034 & There are differences \\
\hline
\end{tabular}


The statistical tool, 2-way ANOVA, has been used to test the above hypothesis and the results have been summarized in the table 9 below:

Table 9 illustrates that the significant $F$ value is less than the p-value (5\%) for each personal variable. Ultimately, the relationship between the independent variables and the competitive advantage varies according to the variety of the variables.

Table 10. The mean and the standard deviation of the sample's responses

\begin{tabular}{|c|c|c|c|c|}
\hline $\mathrm{N}$ & Phrase & Mean & Standard Deviation & Rate \\
\hline 1. & Creative Service & 4.640 & 0.067 & 2 \\
\hline 2. & Creative Pricing & 4.760 & 0.842 & 1 \\
\hline 3. & Creative Promotion & 4.140 & 0.876 & 3 \\
\hline 4. & Creative Placement (Distribution) & 3.825 & 0.998 & 6 \\
\hline 5. & Creative people & 3.900 & 0.948 & 2 \\
\hline 6. & Creative Physical Environment & 3.072 & 0.971 & 15 \\
\hline 7. & Creative Service Delivery Protocol & 3.000 & 0.801 & 16 \\
\hline 8. & Skills and Specialized industrial Knowledge & 2.260 & 0.980 & 19 \\
\hline 9. & The Knowledge of Plans, Techniques, Strategies, and Competitors' Products. & 3.500 & 0.810 & 10 \\
\hline 10. & The Number of the New Competitors & 3.819 & 0.998 & 7 \\
\hline 11. & New Competitors' Products and their Prices & 3.908 & 0.948 & 4 \\
\hline 12. & New Competitors' Commodities and Facilities & 3.814 & 0.914 & 8 \\
\hline 13. & Competitors' Commodities and their Prices & 3.643 & 1.067 & 9 \\
\hline 14. & The Ways of Classifying Competitors & 3.255 & 1.1036 & 12 \\
\hline 15. & Competitors' Ways of Promotion & 3.405 & 0.9282 & 11 \\
\hline 16. & Competitors' Services and Facilities & 3.075 & 0.9711 & 14 \\
\hline 17. & Technology Used by Competitors & 2.907 & 1.1048 & 17 \\
\hline 18. & Competitors' Weakness and Strengthens & 3.155 & 1.0754 & 13 \\
\hline 19. & Competitors' Opportunities and Threats & 2.325 & 1.1183 & 20 \\
\hline 20. & Competitors' Future Aspirations & 3.005 & 1.1048 & 15 \\
\hline
\end{tabular}

\section{Results and Recommendations}

\subsection{Results}

The Study comes up with the following results:

- The necessity to understand and realize the importance of marketing creativity today's business world \& Being a cumulative process, marketing creativity needs continuity due to its properties such as the vanishing property.

- The need to work on sustaining the vitality of marketing creativity and develop as well as maintain its prime asset in the organization creative writing is considered as a strategic asset of the organization which needs more focus from the senior administration in order to be beneficial.

- There is a significant/strong positive relationship between marketing creativity and competitive advantage of the sampled organizations.

- There are differences in the relationship between marketing creativity and competitive advantage due to the personal information of the sample.

- Marketing Creativity contributes to efficiently enhance the competitive advantage since the regression of marketing creativity and competitive advantage equals $0.832+(\mathrm{R}=0.832+)$.

- The statistical analysis indicates that the process of marketing creativity in product, price, promotion, distribution, people, physical environment, and service delivery technique in the sampled organizations is positively agreed on by all the members of the sample as shown in Table 10. The percentages of agreement indicate that the sampled organizations offer creative service marketing mix to the related market. Evidently, this means that the sampled organizations have a clear marketing vision and strategies related to the markets and customers. Following the changes in the markets, these organizations change their products trying to meet their customers' constant needs. 
- As for the variables of the study, the statistical analysis reveals that the responses of the sample are relatively positive since the members of the study agree that their organizations are trying to achieve their objectives taking into consideration the competitive advantages.

- As for the analysis of the relations among the study independent and dependent variables, there are positive relations among those variables. Accordingly, this leads to conclude that there is a significant relationship between the independent variables of the study. These results reflect the significance of the relation between marketing creativity and competitive advantages of the sampled organizations due to the role of marketing creativity in enhancing the organizations' status and entrepreneurship in the market.

- As for the results of the simple linear regression, they point to the relations, influences, and significances of/among the independent and dependent variables of the competitive advantages in marketing creativity. Accordingly, the majority of statistical analysis indicates that there is a significant positive influence of all the variables of marketing creativity (products, price, promotion, placement, people, physical environment, Service delivery protocol) on the competitive advantages that in turn enhances the power of the default proposal of the study.

\subsection{Recommendations}

1). Founding a marketing section within the organization responsible for developing and creating new products run by people highly qualified and creative in Marketing

2). Creating a balance among the various areas of marketing and not focusing only on the product in spite of its significant in the process

3). Establishing a system of incentives and rewards given for individuals who contribute in the creative process encouraging workers to work on creative marketing and using the box of ideas since the creative marketing starts with an idea

4). Forming a specialized team which is willing to go for adventurous experiences to collect new ideas, work on them, and turn them into innovative products which can be entered into the market and be registered as a patent for the organization.

5). Paying a special attention to research and development most particularly on how to develop current products and create new ones making use of the ideas, data, information gained through surveys, questionnaires, and the box of complaints and suggestions; and cooperating with other organizations, scientific research institutions, and universities in the field.

6). Taking into consideration the use of modern marketing methods since it is a good indicator of level the organization has reached so far in terms of production, marketing, technology, and other areas.

7). Making use of research activities and employ them to serve creative marketing not focusing only on conventional products already known by the clients. The organization needs not to concentrate on providing less risky products and tries to develop the risky products

8). Keeping track with the constant developments in the competing local organizations to benefit from the ideas and experiences and taking the initiative to search for and adopt new ideas systematically by founding its own marketing intelligence section.

9). Developing an integrated information system specialized in the research for and the development of creative ideas for any organization needs to have a reservoir of ideas and suggestion in order for usage and experiment

10). Taking into consideration the average salaries of the clients when pricing the products, with special attention to quality and details, and following modern pricing methods in a way that attract more clients and keep them loyal to the organization

11). Implementing modern marketing methods, cheaper and faster, which make it easier to contact with clients using satellite channels, internet, and other

12). Conducting regular evaluation for creative marketing mix to find out causes of failure and success, enforce the success, handle the failure, and establishing the right marketing fundamentals attracting the clients to be more responsive.

13). Establishing an administration specialized generally in creativity and most particularly in marketing creativity in each sampled organization and necessarily paying attention to look for, filter, and evaluate vital marketing ideas and turn the useful ideas into innovative, developed, and tangible ones mainly serving the customers of an organization. 


\section{References}

Ali, Z. (2016a). A leader in business organizations - the marginal-first century industry. United Arab Emirates: Dar University Book Publishing.

Ali, Z. (2016b). The foundations of scientific and assets in entrepreneurship and small and medium-sized organizations. United Arab Emirates: Dar University Book Publishing.

Allen, H. (2013). Innovations in retail payments: e-payments. Asia-Pacific Journal of Accounting \& Economics, 4.

Anisa, P. (2006). Innovation marketing. Journal of Economic and political, 5(1).

Benfratello, L., Schiantarelli, F., \& Sembenelli, A. (2008). Banks and innovation: Microeconometric evidence on Italian firms. Journal of Financial Economics, 90. https://doi.org/10.1016/j.jfineco.2008.01.001

Bonnal, P. (2009). Management of Innovation Organization. Innovation and $R \& D$, Tuesday, Sept. 21.

Braffin, J. (2008). Creative Managment in the 21th Century. In A. A. Maghribi (trans.). Dar Al Fajir, Cairo.

Chen, Y. (2006). Marketing Innovation. Journal of Economics \& Management Strategy, 15(1), 101-123. https://doi.org/10.1111/j.1530-9134.2006.00093.x

Cook, P. (2007). Creative Mannagement. In K. A. Omari (trans.). Dar Al Farouq, Cairo.

Garibaldi, G. (2009). Innovation Management. UK: McGraw Hill Higher Robert Education.

Khudiar, K. (2008). Knowledge Organization. Dar Al Safaa, Amman.

Lammer, T. et al. (2009). Payment Habits and the Adoption of Payment Innovations, Retail Payments-Integration and innovation. A joint conference by the European Central Bank and De Nederlandsche Bank, 25-26 May.

Moore, A. M. (2004). Darwin and the demon: innovating within established enterprises. Harvard Business Review, 82(7-8), 96-92, 187.

$\mathrm{Na}$ 'eem, A. J. (2003). Innovative Marketing. Arab Association for Administrative Development.

Porter, M. (2009). Competitive Advantage of Nations. Inter Edition.

Sami, H. (2008). Management by ideas. Dar Al Raya, Amman, Jordan.

Sanjeef, S., \& Rajesh, K. P. (2005). Entrepreneurship, Innovation and Marketing: Conceptualization of Critical Linkages. Journal of Advances in Management Research, 2(1).

Singh, M., \& Waddell, D. (2014). E-Business Innovation and Change Management. USA: Idea Group Publishing.

Soparnot, R., \& Stevens, E. (2007). Innovation Management. How to establish strategic innovation? Paris: Wiley.

\section{Copyrights}

Copyright for this article is retained by the author, with first publication rights granted to the journal.

This is an open-access article distributed under the terms and conditions of the Creative Commons Attribution license (http://creativecommons.org/licenses/by/4.0/). 